\title{
Traditional Chinese Medicine Curcumin Sensitizes Human Colon Cancer to Radiation by Altering the Expression of DNA Repair-related Genes
}

\author{
GUANGEN YANG ${ }^{1}$, JIANMING QIU ${ }^{1}$, DONG WANG ${ }^{1}$, YONG TAO ${ }^{2}$, YIHUAN SONG $^{1}$, HONGTAO WANG ${ }^{1}$, \\ JUPING TANG ${ }^{1}$, XING WANG $^{3}$, YU SUN ${ }^{4}$, ZHIJIAN YANG ${ }^{4,5}$ and ROBERT M. HOFFMAN ${ }^{5,6}$ \\ ${ }^{1}$ Hangzhou Third Hospital, Hangzhou, P.R. China; \\ ${ }^{2}$ Department of Colorectal Surgery, Affiliated Hangzhou Third Hospital of Zhejiang, \\ Chinese Medicine University, Hangzhou, P.R. China; \\ ${ }^{3}$ Beijing Huairou District Hospital of Chinese Medicine, Beijing, P.R. China; \\ ${ }^{4}$ Origin Biosciences Inc., Nanjing, P.R. China; \\ ${ }^{5}$ AntiCancer, Inc., San Diego, CA, U.S.A.; \\ ${ }^{6}$ Department of Surgery, University of California, San Diego, CA, U.S.A.
}

\begin{abstract}
Background/Aim: The aim of the present study was to investigate the radio-sensitizing efficacy of curcumin, a traditional Chinese medicine (TCM) on colon cancer cells in vitro and in vivo. Materials and Methods: Human colon cancer HT-29 cells were treated with curcumin $(2.5 \mu M)$, irradiation $(10 \mathrm{~Gy})$ and the combination of irradiation and curcumin. Cell proliferation was assessed using the MTT assay. Apoptotic cells were detected by Annexin V-PE/7-AAD analysis. PCR was performed to determine differentialexpression profiling of 95 DNA-repair genes in irradiated cells and cells treated with both irradiation and curcumin. Differentially-expressed genes were confirmed by Western blotting. In vivo radio-sensitizing efficacy of curcumin was assessed in a xenograft mouse model of HT-29 colon cancer. Curcumin was administrated daily by intraperitoneal injection at $20 \mathrm{mg} / \mathrm{kg} /$ dose. Mice received irradiation (10 Gy) twice weekly. Apoptosis of the cancer cells following treatment was determined by TUNEL staining. Results: Irradiation induced proliferation inhibition and apoptosis of HT-29 cells in vitro. Concurrent curcumin treatment sensitized the HT-29 tumor to irradiation $(p<0.01)$. DNA repair-related genes $C C N H$ and $X R C C 5$ were upregulated and LIG4 and PNKP downregulated by the combination of curcumin and irradiation compared with irradiation alone
\end{abstract}

Correspondence to: Jianming Qiu, Hangzhou Third Hospital, Hangzhou, P.R. China. Tel: +86 57187827265, e-mail: 15168427344@163.com

Key Words: Curcumin, radiosensitivity, DNA repair gene, colon cancer. $(p<0.05)$. Combined treatment of curcumin and irradiation resulted in a significantly greater tumor-growth inhibition and apoptosis compared to irradiation treatment alone $(p<0.01)$. Conclusion: Curcumin sensitizes human colon cancer in vitro and in vivo to radiation. Downregulation of LIG4 and PNKP and upregulation of XRCC5 and CCNH $D N A$-repair-related genes were involved in the radiosensitizing efficacy of curcumin in colon cancer.

Curcumin [1,7-bis (4-hydroxy-3-methoxyphenyl)-1,6heptadiene-3,5dione] is a traditional Chinese medicine (TCM) derived from the rhizome of Curcuma longa (1). Curcumin has been shown to inhibit cancer-cell proliferation and induce cell apoptosis in many types of cancer cells (17) and modulate multiple cell-signaling pathways (8). Additionally, curcumin induces radio-sensitivity of cancer cells in vitro and in vivo (9-11). Curcumin also alters the expression of radio-sensitivity-related signaling pathways $(12,13)$. The detailed mechanism of the radio-sensitizing effects of curcumin on colon cancer is poorly understood.

In the present study, we investigated the radio-sensitizing efficacy of curcumin on the proliferation and apoptosis of colon cancer cells in vitro and tumor growth in a xenograft model of human colon cancer. To determine the mechanism of radio-sensitization, we performed a real-time polymerase chain reaction (PCR) assay in order to identify DNA-repair genes involved in the radio-sensitizing mechanism of curcumin.

\section{Materials and Methods}

Colon cancer cells and culture. Human colon-cancer cell line (HT29) was purchased from the Shanghai Cell Bank of the Chinese 
Academy of Sciences. Cells were cultured in RPMI 1640 medium (Thermo Fisher Scientific, CA, USA) containing 10\% fetal bovine serum (Thermo Fisher Scientific, CA, USA), $100 \mathrm{U} / \mathrm{ml}$ penicillin and $100 \mu \mathrm{g} / \mathrm{ml}$ streptomycin (Thermo Fisher Scientific, CA, USA) at $37^{\circ} \mathrm{C}$ with $5 \% \mathrm{CO}_{2}$.

Cell proliferation assay. Cell proliferation was determined using the MTT assay. HT-29 cells were seeded in 96-well plates with $5 \times 10^{3} / 200 \mu \mathrm{l}$ and cultured overnight. Cells were divided into four groups: control group; curcumin group; irradiation group (IR); and irradiation + curcumin (IR+curcumin) group. Cells treated with dimethyl sulfoxide $(0.1 \%$ DMSO) were used as a vehicle control. Each treatment included six duplicate wells. The curcumin and IR+curcumin groups were treated with $2.5 \mu \mathrm{M}$ curcumin $(94 \%$ purity, Sigma, St. Louis, MO, USA). The IR and IR+curcumin groups were irradiated with $\mathrm{X}$ ray at $6 \mathrm{MV}$ using a $600 \mathrm{C} / \mathrm{D}$ linear accelerator (RS2000Pro, RADSOURCE, Buford, GA, USA) to deliver the indicated doses $(10 \mathrm{~Gy})$. All cells were further cultured for 24,48 , or $72 \mathrm{~h}$. To measure cell viability, $20 \mu \mathrm{l} \mathrm{3-(4,5-}$ dimethylthiazol-2-yl)-2,5-diphenyltetrazolium bromide (MTT) (5 $\mu \mathrm{g} / \mu \mathrm{l})$ (ATCC, Manassas, VA, USA) were added to each well and incubated for $2 \mathrm{~h}$ at $37^{\circ} \mathrm{C}$. An extraction buffer (20\% SDS and 50\% dimethylformamide) was added, and the cells were incubated overnight at $37^{\circ} \mathrm{C}$. The absorbance (OD) at $490 \mathrm{~nm}$ was measured with a micro-plate reader to determine the cell viability. The above experiment was repeated three times. The resulting MTT absorbance in negative control cells was used as $0 \%$ cell inhibition.

Annexin V detection of apoptotic cells. Apoptotic cells were detected by Annexin V-PE/7-AAD analysis. Cells were divided into four groups (Control; curcumin; IR; and IR+curcumin group) $\left(5 \times 10^{5}\right.$ cells/well) and seeded in 6-well plates. After attachment to the dish, the cells in the curcumin and radiation+curcumin were treated with $2.5 \mu \mathrm{M}$ curcumin. The IR and IR+curcumin groups were treated with $\mathrm{X}$ ray at $6 \mathrm{MV}$ using a $600 \mathrm{C} / \mathrm{D}$ linear accelerator to deliver the indicated doses (10Gy). All cells were further cultured for $48 \mathrm{~h}$. Cells were digested by $0.25 \%$ trypsin without EDTA (Thermo Fisher Scientific, CA, USA) and then were stained using an Annexin VPE/7-AAD apoptosis kit (Nanjing KeyGen BioTech, Nanjing, P.R.China) according to the manufacturer's instructions. Stained cells were detected and analyzed using flow cytometry (Becton Dickinson, NJ, USA). Each experiment was performed in triplicate.

Real-time PCR array analysis of gene expression. Samples from each group were submerged in $2 \mathrm{ml}$ Trizol (Invitrogen, Carlsbad, CA, USA) for RNA extraction and stored at $-80^{\circ} \mathrm{C}$ until further processed. cDNA synthesis was performed on $4 \mu \mathrm{g}$ RNA in a $10 \mu$ sample volume using SuperScript II reverse transcriptase (Invitrogen) as recommended by the manufacturer. Real-time PCR array analysis was performed in a total volume of $20 \mu \mathrm{l}$ including $1 \mu \mathrm{l}$ cDNA, $10 \mu \mathrm{l}$ qPCR Master Mix 2x (Roche, Mannheim, Germany) and $9 \mu \mathrm{ddH}_{2} \mathrm{O}$. Reactions were run on an Lightcycler 480 (Roche) using universal thermal cycling parameters $\left(95^{\circ} \mathrm{C}\right.$ for $5 \mathrm{~min}, 40$ cycles of $15 \mathrm{sec}$ at $95^{\circ} \mathrm{C}, 15 \mathrm{sec}$ at $60^{\circ} \mathrm{C}$ and $20 \mathrm{sec}$ at $72^{\circ} \mathrm{C}$; followed by a melting curve: $5 \mathrm{sec}$ at $95^{\circ} \mathrm{C}, 60 \mathrm{sec}$ at $60^{\circ} \mathrm{C}$ and continued melting). Data were obtained using the Lightcycler 480 sequence detection software and analyzed using Microsoft Excel. For quality control purposes, melting curves were acquired for all samples. The comparative $\mathrm{Ct}$ method was used to quantify gene expression. The target gene expression level was normalized to expression of the housekeeping gene glyceraldehyde 3-phosphate dehydrogenase (GAPDH) within the same sample $(-\Delta \mathrm{Ct})$. The relative expression of each gene was calculated using $\log 2(-\Delta \mathrm{Ct})$.

Western blotting. The differential gene expression of CCNH, LIG4, XRCC5 and PNKP in the various groups was determined by Western blotting. Cells were lysed in $100 \mu \mathrm{l}$ RIPA lysis buffer $(50 \mathrm{mmol} / \mathrm{l}$ Tris$\mathrm{HCl}, \mathrm{pH} 7.5,1 \% \mathrm{NP}-40,150 \mathrm{mmol} / \mathrm{l} \mathrm{NaCl}, 1 \mathrm{mg} / \mathrm{ml}$ aprotinin, $1 \mathrm{mg} / \mathrm{ml}$ leupeptin, $1 \mathrm{mmol} / 1 \mathrm{Na}_{3} \mathrm{VO}_{4}, 1 \mathrm{mmol} / \mathrm{l} \mathrm{NaF}$ ) at $4{ }^{\circ} \mathrm{C}$ for $30 \mathrm{~min}$. Cell debris was removed by centrifugation at $12,000 \times g$ for $20 \mathrm{~min}$ at $4^{\circ} \mathrm{C}$. Protein concentrations were determined with the Bradford assay (BioRed, Hercules, CA, USA). An equal amount of lysate ( $40 \mu \mathrm{g})$ was resolved by sodium dodecyl sulfate (SDS) polyacrylamide gel electrophoresis and transferred to a polyvinylidene difluoride membrane (Millipore, Bedford, MA, USA). The membranes were blocked with 5\% non-fat milk at room temperature for $1 \mathrm{~h}$ and then incubated for $2 \mathrm{~h}$ with primary antibodies to CCNH, LIG4, XRCC or PNKP (Cell Signaling Technology, Boston, MA, USA). The membranes were then incubated for $1 \mathrm{~h}$ with an appropriate horseradish peroxidase-linked secondary antibody (Santa Cruz Biotechnology, Dallas, TX, USA). Electro-chemiluminescence was performed according to the manufacturer's instructions using a ChemiDoc ${ }^{\mathrm{TM}}$ Touch Imaging System (Bio-Rad, Hercules, California, USA). Quantity One software (Bio-Rad, Hercules, CA, USA) was used to quantify band density.

Animal care. Twenty-eight [28] BALB/C female nude mice aged 46 weeks weighing 20-25g, were purchased from Shanghai SLAC Laboratory Animal Co., Ltd., Shanghai, P.R.China (SCXK, Hu. 2007-0005). All mice were maintained in a HEPA-filtered environment at $24-25^{\circ} \mathrm{C}$ and humidity was maintained at $50-60 \%$. All animals were fed with autoclaved laboratory rodent diet. Animal experiments were approved by the Animal Committee of Nanjing Origin Biosciences, P.R. China (OB1431).

In vivo anti-tumor efficacy. A mouse model of human colon cancer [14] was established with the HT-29 cancer cell line. Stocks of HT29 tumors were established by subcutaneously injecting $5 \times 10^{6}$ HT29 cells in the flank of nude mice. The resulting tumors were harvested at the exponential growth phase and resected under aseptic conditions. Necrotic tissues were removed and viable tissues were cut with scissors and minced into $1-\mathrm{mm}^{3}$ pieces. Animals were anesthetized by injection of $0.02 \mathrm{ml}$ of solution of $50 \%$ ketamine, $38 \%$ xylazine, and 12\% acepromazine maleate. Two tumor fragments were transplanted to the flank of nude mice. All surgical procedures and animal manipulations were conducted under HEPAfiltered laminar-flow hoods.

Treatments were initiated when the average tumor size reached $100 \mathrm{~mm}^{3}$. The mice with tumors were randomly divided into four groups of seven. Group 1 (Control) received intraperitoneal saline injection only; Group 2 (curcumin); Group 3 received irradiation; Group 4 (irradiation and curcumin) received intraperitoneal curcumin treatment at $20 \mathrm{mg} / \mathrm{kg} /$ dose. Six hours after saline or curcumin treatment, Groups 3 and 4 received irradiation (10 Gy). For irradiation, animals were anesthetized and immobilized in the treatment position with their right legs extended. Radiation was delivered at a dose rate of $2.0 \mathrm{~Gy} / \mathrm{min}$ through a single posterior to anterior collimated $3-\mathrm{cm}$ cobalt beam with a $5-\mathrm{mm}$ bolus placed over the tumor. Tumor growth was measured twice a week with calipers. Tumor volume was calculated using the formula $\left(\mathrm{L} \times \mathrm{W}^{2}\right) \times 1 / 2$, where $\mathrm{W}$ and $\mathrm{L}$ represent the perpendicular minor dimension and 


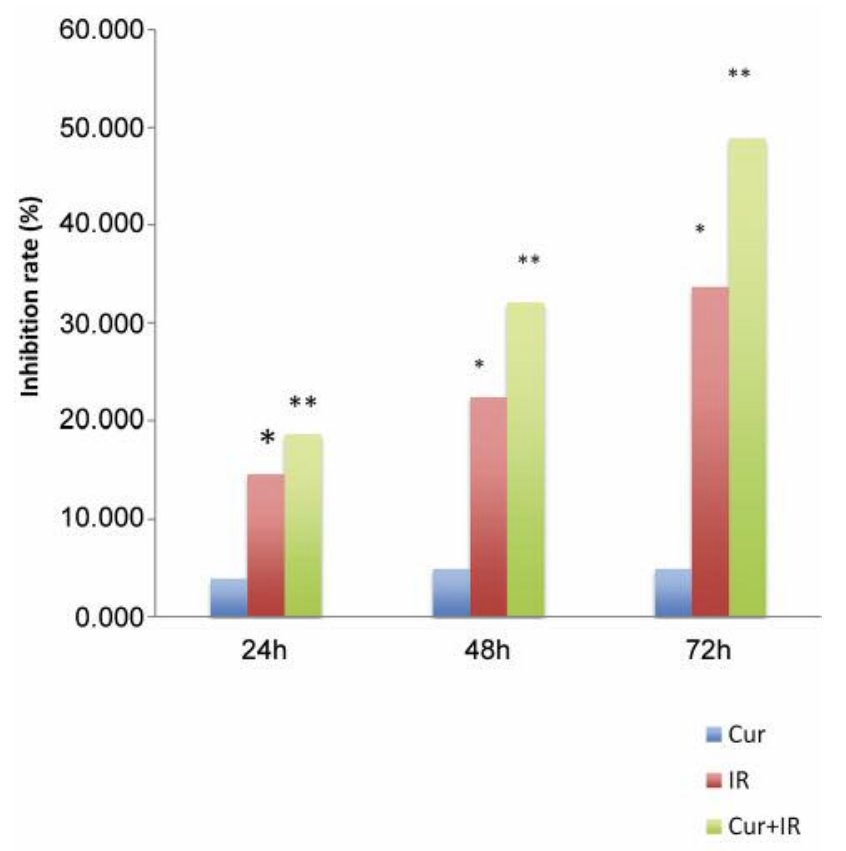

Figure 1. Curcumin sensitizes colon cancer cells to radiation (IR). Cell proliferation was measured using the MTT assay as described in the Materials and Methods. IR had significantly greater proliferation inhibition on HT-29 cells than curcumin at each time point. IR-induced proliferation inhibition was significantly increased by combination curcumin treatment compared with IR-alone at each time point. ${ }^{*} p<0.01$, when compared with curcumin. ${ }^{*} p<0.01$, when compared with IR. Cur: Curcumin; IR: irradiation.

major dimension, respectively. Animal body weights and clinical signs were recorded over the course of the experiments. All animals were sacrificed 15 days after treatment initiation. At autopsy the tumor was removed and weighed. The tumor tissue was formalinfixed and paraffin-embedded for further analysis.

TUNEL detection of apoptosis. Apoptosis of the tumor cells following in vivo treatment was determined by TUNEL staining, using a commercially-available kit (In Situ Cell Death Detection Kit, POD; Roche). Tumor sections were deparaffinized and dehydrated according to standard protocols. Tissue sections were incubated with Proteinase $\mathrm{K}$ working solution for $30 \mathrm{~min}$ at $21-37^{\circ} \mathrm{C}$. The slides were then washed with PBS (pH 7.2-7.6) twice. The positive control was incubated with DNase I for $10 \mathrm{~min}$ at $15-25^{\circ} \mathrm{C}$. The negative control was incubated with label solution (without terminal transferase) instead of the TUNEL reaction mixture. The slides were then washed with PBS (pH 7.2-7.6) three times. Converter-POD was added on the slides which were then incubated in a humidified chamber for $30 \mathrm{~min}$ at $37^{\circ} \mathrm{C}$. The slides were then washed with PBS ( $\mathrm{pH}$ 7.2-7.6) three times. DAB substrate was added on the slides which were then incubated for $10 \mathrm{~min}$ at $15-25^{\circ} \mathrm{C}$. The slides were then washed with PBS ( $\mathrm{pH}$ 7.2-7.6) three times. The slides were mounted and analyzed by microscopy (Olympus, Melville, NY, USA). The apoptotic index (AI) was calculated by counting the number of $\mathrm{TUNEL}^{+}$nuclei visible with a high-power-field 40x

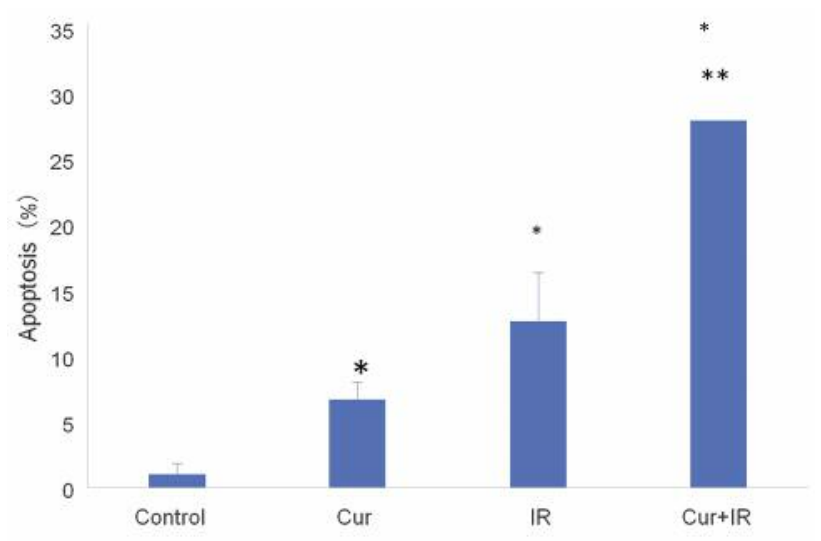

Figure 2. Curcumin potentiates IR-induced cancer-cell apoptosis. Apoptotic cells were detected with Annexin V-PE/7-AAD as described in the Materials and Methods. All treatments increased cancer-cell apoptosis compared with the control. IR-induced cancer-cell apoptosis was significantly increased by curcumin as compared with IR-alone. ${ }^{*} p<0.01$, when compared with IR-alone. ${ }^{* *} p<0.01$, when compared with IR-alone. Cur: Curcumin; IR: irradiation.

objective in at least 3 fields/sample. The results were expressed as the percentage of apoptotic cells with respect to the total number of cells in each field. Apoptotic cells were identified by the appearance of brown- or tan-stained nuclei.

Statistical analysis. Data are expressed as means $\pm \mathrm{SD}$, and were analyzed by one-way analysis of variance (ANOVA), using SPSS software version 19.0, where $p<0.05$ was considered to be statistically significant.

\section{Results and Discussion}

Curcumin sensitizes HT-29 cells to radiation. As shown in Figure 1, irradiation (IR) induced significantly greater proliferation inhibition of HT-29 cells than curcumin treatment at each time point $(p<0.01)$. However, IR-induced proliferation inhibition was significantly increased by combination curcumin treatment $(p<0.01)$.

Curcumin potentiates IR-induced cancer-cell apoptosis. As shown in Figure 2, IR induced significant cancer-cell apoptosis $(13.11 \%)$ compared with curcumin $(6.91 \%) \quad(p<0.01)$. IRinduced cell apoptosis was significantly increased by curcumin $(27.92 \%)$ compared with IR-alone $(p<0.01)$.

Curcumin sensitizes cancer cells to IR by altering the expression of DNA-repair-related genes. PCR was performed to compare differential-expression profiling of 95 DNA repairrelated genes between the cells treated with IR-alone and the cells treated with both IR and curcumin. Four DNA repairrelated genes had significant differential expression, including CCNH, LIG4, XRCC5 and PNKP (Figure 3A). CCNH and 


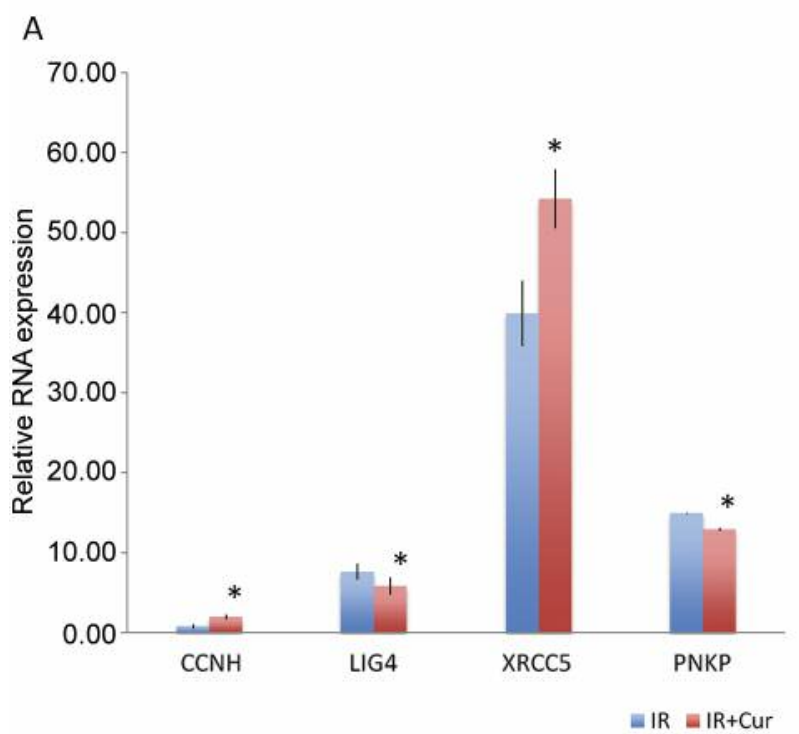

B
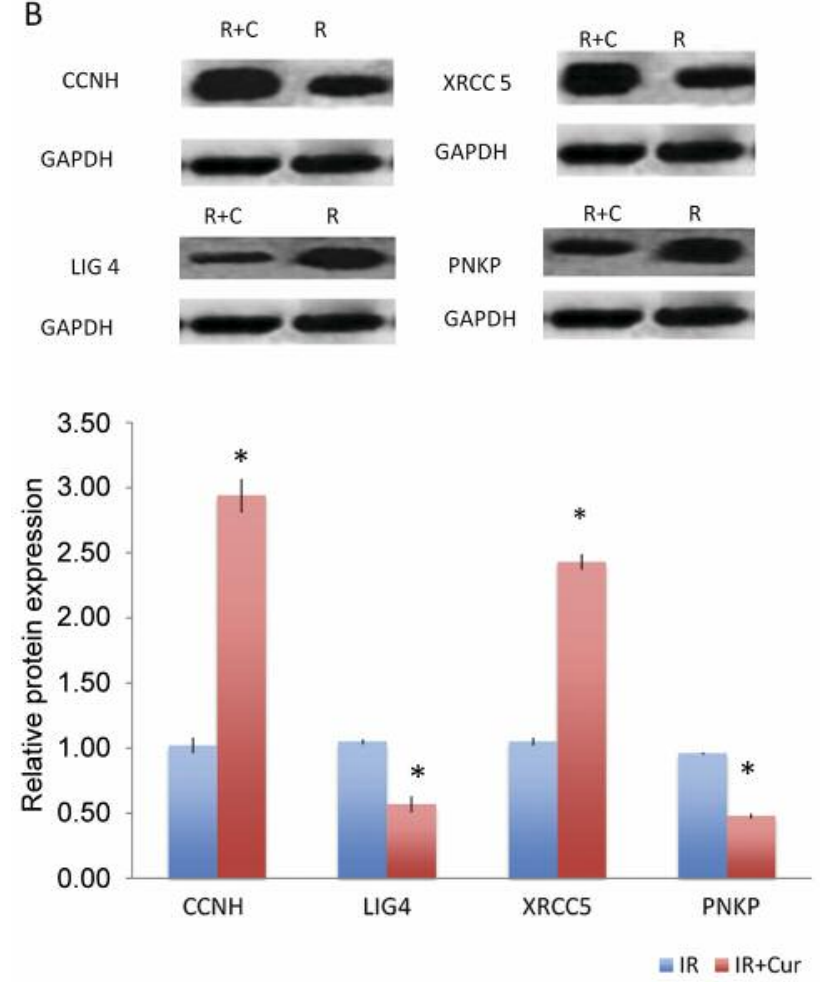

Figure 3. Curcumin sensitizes cancer cells to IR by altering the expression of DNA repair-related genes. (A) PCR was performed to determine differential-expression profiling of 95 DNA repair genes between the IR and IR plus curcumin groups as described in the Materials and Methods. $C C N H$ and XRCC5 $\mathrm{mRNA}$ expression was upregulated by $I R+$ curcumin compared to IR-alone. LIG4 and PNKP mRNA expression was downregulated by the combination of $I R$ and curcumin compared to IR-alone. ${ }^{*} p<0.05$, when compared with IR. (B) The differential protein expression of four DNA-repair-related genes was confirmed by Western blotting as described in the Materials and Methods. ${ }^{*} p<0.05$, when compared with IR. Cur: Curcumin; IR: irradiation.

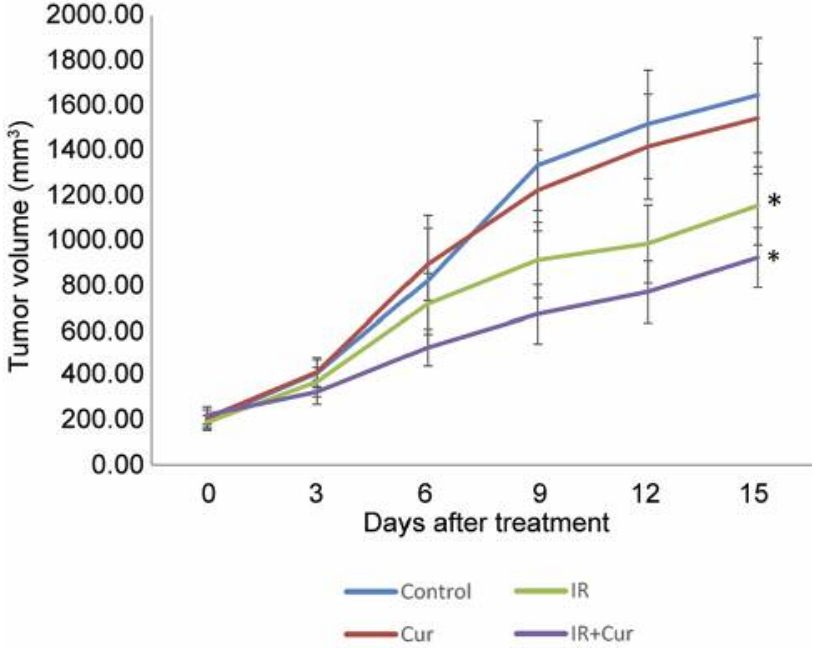

Figure 4. Curcumin sensitizes colorectal cancer to IR in vivo. The effect of curcumin on tumor radio-sensitivity was assessed on a human colon cancer HT-29 xenograft tumor as described in the Materials and Methods. Tumor growth was significantly reduced by $I R$ and by $I R$ combined with curcumin compared to the control group. IR plus curcumin resulted in significantly greater tumor-growth inhibition compared to IR alone. ${ }^{*} p<0.01$, when compared with the control. $* * p<0.01$, when compared with IR. Cur: Curcurmin; IR: irradiation.

XRCC5 mRNA expression was up-regulated 2.49- and 2.15fold, respectively, in the cells treated with both IR and curcumin compared to the cells treated only with IR $(p<0.05)$. LIG4 and PNKP mRNA expression was down-regulated 2.63and 1.70-fold, respectively in the cells treated with both IR and curcumin compared to cells treated with IR-only $(p<0.05)$.

The differential expression of four DNA repair-related genes was confirmed by Western blot analysis of protein expression. As shown in Figure 3B, the IR and curcumintreated group had higher protein expression of $\mathrm{CCNH}$ and XRCC5 and lower protein expression of LIG4 and PNKP, compared to the IR-alone treated group.

Curcumin sensitized the HT29 colorectal tumor to IR in vivo. To determine whether curcumin can sensitize colorectal cancer to IR in vivo, we examined the effect of curcumin alone, IR alone or the combination of curcumin and IR on the growth of subcutaneous HT-29 tumors in nude mice. As shown in Figure 4 , the curcumin group did not show significant tumor growth inhibition compared to the control group $(\mathrm{p}>0.05)$. However, tumor growth was significantly reduced by IR and by the combination of IR and curcumin compared to the control group starting from day 9 after treatment initiation (both $p<0.01$ ). Combined treatment with IR and curcumin resulted in significantly greater tumor growth inhibition compared to IR alone $(p<0.01)$. 

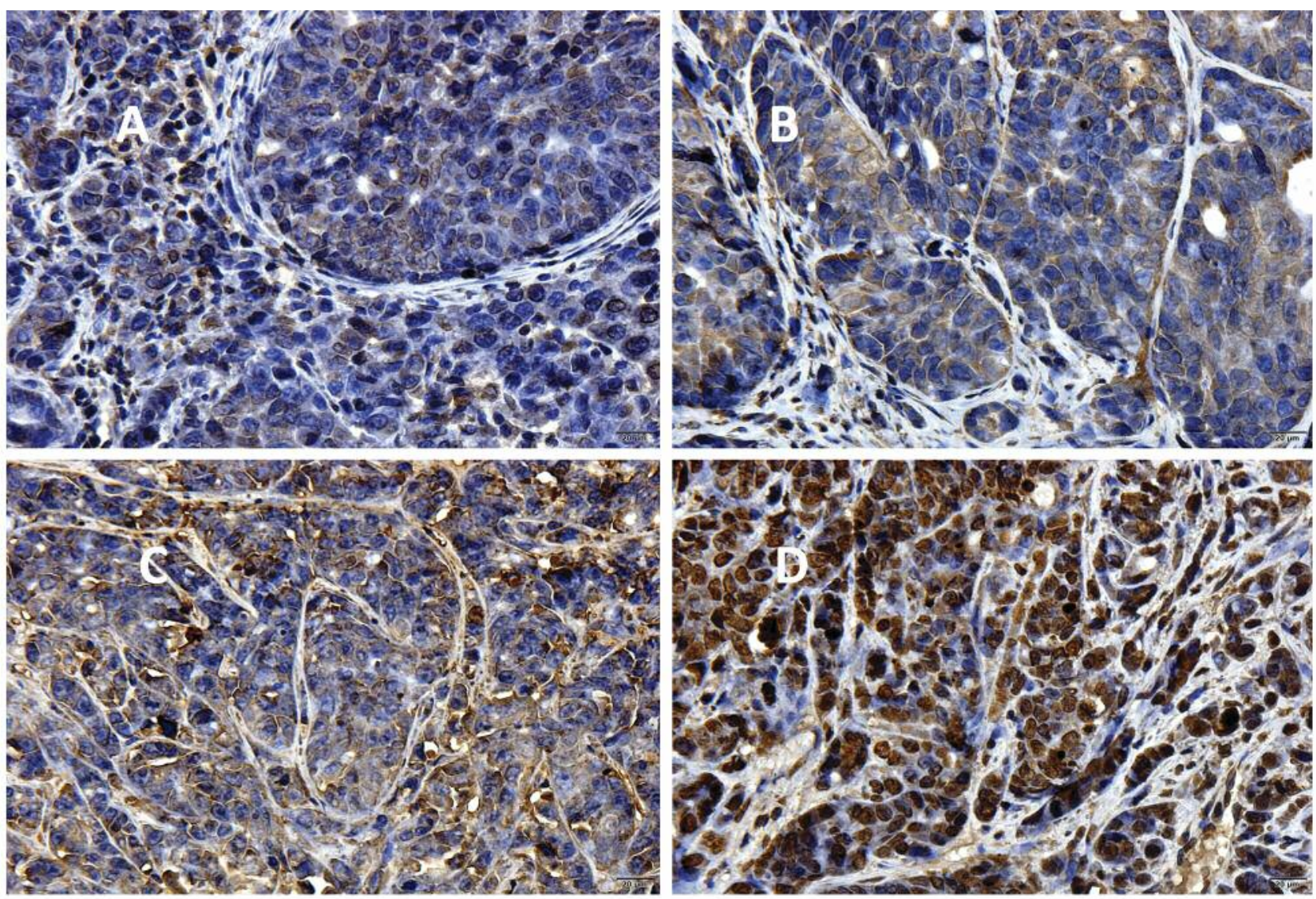

$\mathrm{E}$

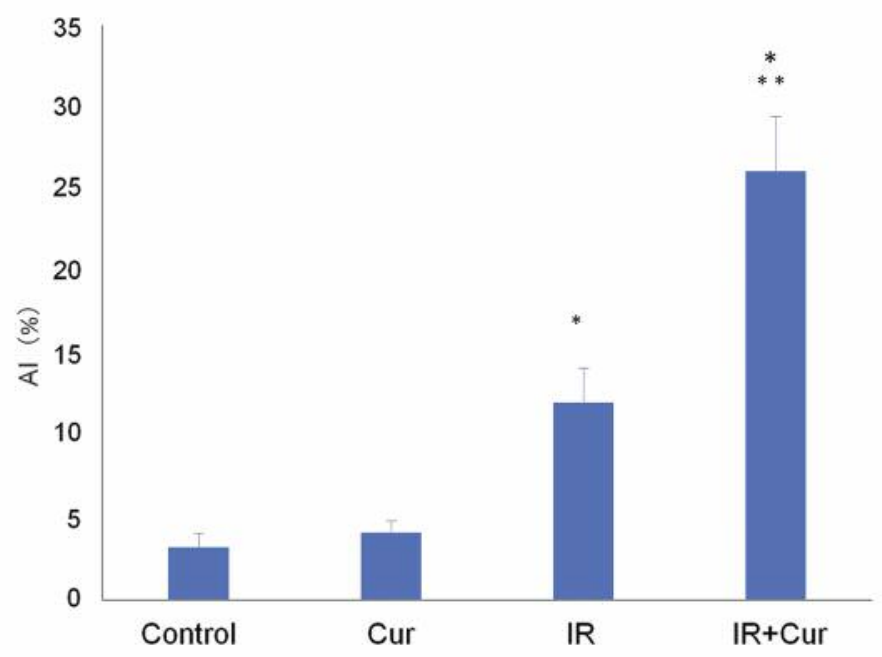

Figure 5. Curcumin increased IR-induced tumor apoptosis in vivo. Apoptosis was detected by TUNEL staining as described in the Materials and Methods. (A-D) Representative TUNEL images for cell apoptosis in each group (100x magnification). A: Control; B: Curcumin; C: IR; D: IR plus curcumin. (E) Quantitation of cell apoptosis with the apoptosis index $(A I) .{ }^{*} p<0.01$, compared with the control. ${ }^{*} p<0.01$, compared with IR-alone.

Curcumin increased IR-induced tumor apoptosis in vivo. To investigate the effect of curcumin on IR-induced tumor apoptosis in vivo, we analyzed the apoptosis of the tumor tissues by TUNEL staining. Representative fields of view from each group are shown in Figure 5A-D. The curcumin group did not show significant tumor apoptosis compared to 
the control group $(\mathrm{p}>0.05)$. However, combination treatment of IR and curcumin induced greater tumor apoptosis than IR treatment alone $(p<0.01)$ (Figure 5E).

The LIG4 gene encodes ATP-dependent DNA ligase IV which is involved in the repair of DNA double-strand breaks (DSBs). LIG4 somatic-knockout cell lines display extreme radiation sensitivity $(15,16)$. Polynucleotide-kinase phosphatase (PNKP) is a DNA repair enzyme which plays a critical role in radiation-induced DNA-end repair (17). X-ray repair crosscomplementing 5 (XRCC5), encoding the Ku80 protein, is an important functional factor in the $N H E J$ repair pathway (18). If the NHEJ repair gene is defective, the cells have increased their radiation sensitivity (19). $\mathrm{CCNH}$ is mainly involved in the regulation of cyclin-dependent protein kinases and is also involved with RNA polymerase II (20). Our results indicated that curcumin enhanced the radio-sensitivity of human colon cancer cells via down-regulation of LIG4 and PNKP expression and up-regulation of XRCC5 and CCNH expression (Figure 3).

The present study demonstrates the potential of a traditional Chinese medicine (curcumin) as an effective radio-sensitizer for human colon cancer.

\section{Conflicts of Interest}

None of the Authors have a conflict of interest in regard to this study.

\section{Acknowledgements}

This research was supported by the Natural Science Foundation of Zhejiang Province (No.LY15H160001), the Medical Funds for Special Diseases in Key Department of Hangzhou (No.20160533B27 and 20150733Q28) and the Key Science Fund of Hangzhou Health Bureau (No.201764522).

\section{References}

1 Campbell FC and Collett GP: Chemopreventive properties of curcumin. Future Oncol 1: 405-414, 2005.

2 Sarkar FH and Li Y: Cell signaling pathways altered by natural chemopreventive agents. Mutat Res 555: 53-64, 2004.

3 Dorai T, Cao YC, Dorai B, Buttyan R and Katz AE: Therapeutic potential of curcumin in human prostate cancer. III. Curcumin inhibits proliferation, induces apoptosis, and inhibits angiogenesis of LNCaP prostate cancer cells in vivo. Prostate 47: 293-303, 2001.

4 Han SS, Chung ST, Robertson DA, Ranjan D and Bondada S: Curcumin causes the growth arrest and apoptosis of B cell lymphoma by downregulation of egr-1, c-myc, bcl-XL, NFkappa $\mathrm{B}$, and p53. Clin Immunol 93: 152-161, 1999.

5 Liu E, Wu J, Cao W, Zhang J, Liu W, Jiang X and Zhang X: Curcumin induces $\mathrm{G}_{2} / \mathrm{M}$ cell cycle arrest in a p53-dependent manner and upregulates ING4 expression in human glioma. J Neurooncol 85: 263-270, 2007.

6 Masuelli L, Benvenuto M, Fantini M, Marzocchella L, Sacchetti P, Di Stefano E, Tresoldi I, Izzi V, Bernardini R, Palumbo C, Mattei M, Lista F, Galvano F, Modesti A and Bei R: Curcumin induces apoptosis in breast cancer cell lines and delays the growth of mammary tumors in neu transgenic mice. J Biol Regul Homeost Agents 27: 105-119, 2013.
7 Yang CL, Ma YG, Xue YX, Liu YY, Xie H and Qiu GR: Curcumin induces small cell lung cancer NCI-H446 cell apoptosis via the reactive oxygen species-mediated mitochondrial pathway and not the cell death receptor pathway. DNA Cell Biol 31: 139-150, 2012.

8 Kunnumakkara $\mathrm{AB}$, Anand $\mathrm{P}$ and Aggarwal BB: Curcumin inhibits proliferation, invasion, angiogenesis and metastasis of different cancers through interaction with multiple cell signaling proteins. Cancer Lett 269: 199-225, 2008.

9 Chendil D, Ranga RS, Meigooni D, Sathishkumar S and Ahmed MM: Curcumin confers radiosensitizing effect in prostate cancer cell line PC-3. Oncogene 23: 1599-1607, 2004.

10 Goel A and Aggarwal BB: Curcumin, the golden spice from Indian saffron, is a chemosensitizer and radiosensitizer for tumors and chemoprotector and radioprotector for normal organs. Nutr Cancer 62: 919-930, 2010.

11 Shehzad A, Park JW, Lee J and Lee YS: Curcumin induces radiosensitivity of in vitro and in vivo cancer models by modulating pre-mRNA processing factor 4 (Prp4). Chem Biol Interact 206: 394-402, 2013.

12 Orr WS, Denbo JW, Saab KR, Ng CY, Wu J, Li K, Garner JM, Morton CL, Du Z, Pfeffer LM and Davidoff AM: Curcumin potentiates rhabdomyosarcoma radiosensitivity by suppressing NF-jB activity. PLoS One 8: 51309, 2013.

13 Pan Y, Wang M, Bu X, Zuo Y, Wang S, Wang D, Liu Q, Su B, $\mathrm{Xu}$ T, Wang C, Claret FX and Yang H: Curcumin analogue T83 exhibits potent antitumor activity and induces radiosensitivity through inactivation of Jab1 in nasopharyngeal carcinoma. BMC Cancer 13: 323, 2013.

14 Kuo T-H, Kubota T, Watanabe M, Furukawa T, Teramoto T, Ishibiki K, Kitajimi M, Moossa AR, Penman S, Hoffman RM: Liver colonization comptence governs colon cancer metastasis. Proc Natl Acad Sci USA 92: 12085-12089, 1995

$15 \mathrm{Kim}$ DH, Oh SY and Kim SY: DNA ligase4 as a prognostic marker in nasopharyngeal cancer patients treated with radiotherapy. Asian Pac J Cancer Prev 15: 10985-10989, 2014.

16 Oh S, Wang Y, Zimbric J and Hendrickson EA: Human LIGIV is synthetically lethal with the loss of Rad54B-dependent recombination and is required for certain chromosome fusion events induced by telomere dysfunction. Nucleic Acids Res 41: 1734-1749, 2013.

17 Coquelle N, Havali-Shahriari Z, Bernstein N, Green R and Glover JN: Structural basis for the phosphatase activity of polynucleotide kinase/phosphatase on single- and double-stranded DNA substrates. Proc Natl Acad Sci USA 108: 21022-21027, 2011.

18 Singleton BK, Priestley A, Steingrimsdottir H, Gell D, Blunt T, Jackson SP, Lehmann AR and Jeggo PA: Molecular and biochemical characterization of xrs mutants defective in $\mathrm{Ku} 80$. Mol Cell Biol 17: 1264-1273, 1997.

19 Bassing CH and Alt FW: The cellular response to general and programmed DNA double strand breaks. DNA Repair (Amst) 3: 781-796, 2004.

20 Fu TJ, Peng J, Lee G, Price DH and Flores O: Cyclin K functions as a CDK9 regulatory subunit and participates in RNA polymerase II transcription. J Biol Chem 274: 34527-34530, 1999.

Received October 5, 2017

Revised October 29, 2017

Accepted October 30, 2017 